\title{
Henry Hyde Salter (1823-71): a biographical sketch
}

\author{
ALEX SAKULA
}

Henry Hyde Salter, the author of the best book on asthma to appear during the nineteenth century, was born on 2 November 1823 in Poole, Dorset, the second son of Thomas Salter FRCS, a successful Dorset surgeon. The family was very much a medical onenot only his father but his grandfather, uncle, and three brothers were all doctors.

Salter matriculated at the University of London, entered King's College in 1844 and graduated with a first class BA in 1846. Influenced by his father, he decided on a career in medicine, pursued his studies at King's College and qualified in 1850. After junior appointments, including the post of demonstrator in anatomy, he proceeded MD in 1851 and settled at 6 Mongatue Street, Russell Square. In 1852 he was appointed physician to the public dispensary in Carey Street.

Salter then transferred his activities to Charing Cross Hospital, where he was appointed assistant physician and lecturer in physiology and pathology in the department of Professor Robert Bentley Todd (1809-60), who occupied the chair of physiology and is today remembered eponymously for "Todd's paralysis." Todd was producing the last two volumes of his Cyclopaedia of Anatomy and Physiology and Salter assisted him in editing these, himself writing two sections, "The Tongue" and "The Pancreas." $\mathrm{He}$ also took part in the completion of Physiological Anatomy under the joint authorship of Todd and Sir William Bowman (1816-92).

In 1856, at the age of 33, Salter became the youngest fellow elected to the Royal College of Physicians and the youngest elected to the fellowship of the Royal Society. The latter honour was bestowed for his physiological work; he was obviously highly regarded since his sponsors, apart from Todd and Bowman, included Richard Owen, John Simon, Thomas Bell, and Thomas Henry Huxley.

Salter had aspirations to succeed Todd in the chair of physiology at Charing Cross but, when this did not happen, he returned in 1854 to his alma mater, King's College, where for the next 12 years he was lecturer in physiology and physiological anatomy and later lecturer in medicine. Despite a slight stammer, he estab-

Address for reprint requests: Dr A Sakula, Pilgrims Corner, Pilgrims Way, Reigate, Surrey RH2 9LG. lished a reputation as a popular teacher. In 1855 he was appointed assistant physician at King's College Hospital and became full physician in 1866 . He was later honoured by being elected a fellow of King's College.

As an infant Salter contracted whooping cough, after which asthma developed. This was severe during his boyhood but became less troublesome as he grew older. During his medical studies and researches the subject of asthma became his special interest. Salter published several papers on asthma but he is chiefly remembered for his magnum opus On Asthma: Its Pathology and Treatment, which was based on his experience of hundreds of cases and no doubt also on his personal sufferings. The text had originally appeared in serial form, chapter by chapter, in

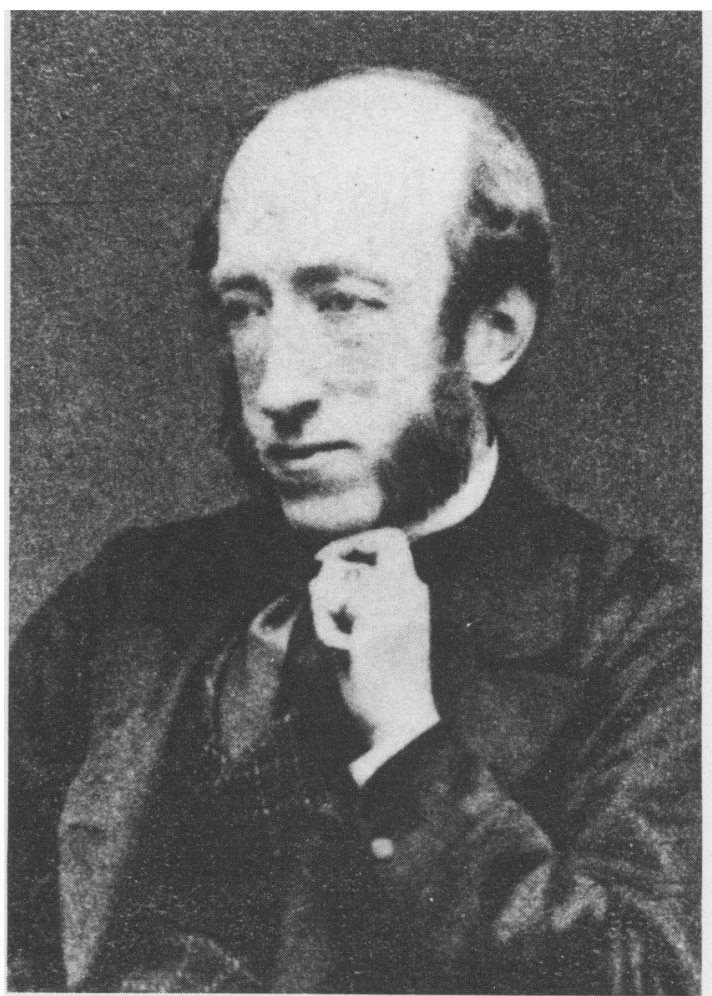

Henry Hyde Salter (1823-71). Reproduced by courtesy of the librarian of the Royal College of Physicians. 
medical journals. Finally, in 1860 the book (372 pages) was published, dedicated "To my relative Thomas Bell, FRs, President of the Linnaean Society."

To the reader of today the book has a remarkably modern "feel." Salter's definition of asthma was: "Paroxysmal dyspnoea of a peculiar character, generally periodic with intervals of healthy respiration between the attacks." The cause of the condition he considered to be "perverted nervous action." Although the concept of allergy had not yet been introduced, Salter was aware of the hereditary nature of asthma and its relation to "idiosyncracies" such as to the emanations of horses, cats, and other animals. Similarly, he appreciated the importance of emotional disturbance in asthma. The treatment he recommended included the usual measures then available, but he was adamant that "Sleep favours asthma." He was therefore opposed to the use of opiates and, for the same reason, advocated hot strong coffee to control the asthmatic attack. The book ends with two appendices of illustrative cases, mostly narrated by the patient in the first person, and it is very likely that case 10 was that of Salter himself.

After the publication of the book, Salter came to be recognised as the authority on asthma and patients flocked to him. An enlarged second edition appeared in 1868 and American editions followed.

Salter's domestic life with his wife and family was a contented one and he enjoyed playing the piano and drawing and painting. Unfortunately at the age of 44 the asthma, from which he had been free for some years, returned with greater severity. In 1871 he developed a febrile illness and typhoid or possibly phthisis was suspected, but the diagnosis proved to be a lung abscess in the right upper lobe, from which he never recovered. He died on 31 August 1871 in his 48th year.

\section{Salter's major publications on asthma}

On asthma, its pathology and treatment. 1st ed-London: J Churchill, 1860 (pp372); 2nd ed-London: J Churchill, 1868 (pp464); 1st American ed-Philadelphia: Blanchard and Lea, 1864 (pp260); 2nd American ed-New York: W Wood, 1882 (pp284).

On some points in the treatment and clinical history of asthma. Edinburgh Medical Journal 1859; 4: 1109-15.

On the treatment of asthma by belladonna. Lancet 1869 ; i: 152-3.

\section{Bibliography}

Anonymous Obituary. Lancet 1871; ii: 415-6.

Anonymous Obituary. $\mathrm{Br}$ Med $\mathrm{J} 1871$; ii:278.

Anonymous Obituary. Medical Times and Gazette 1871; ii: 363-4.

Munk's Roll: Lives of Fellows of Royal College of Physicians of London. Vol 4. London: Royal College of Physicians, 1955: 86.

Persson C G A. On the medical history of xanthines and other remedies for asthma. Thorax 1985; 40: 881-6. 